\title{
Persistent organic pollutants in the green sea turtle Chelonia mydas: nesting population variation, maternal transfer, and effects on development
}

\author{
Jason P. van de Merwe ${ }^{1,5, *}$, Mary Hodge ${ }^{2}$, Joan M. Whittier ${ }^{3,6}$, \\ Kamarruddin Ibrahim ${ }^{4,7}$, Shing Y. Lee ${ }^{1}$ \\ ${ }^{1}$ Griffith School of Environment and Australian Rivers Institute, Griffith University Gold Coast campus, Gold Coast, \\ Queensland 4222, Australia \\ ${ }^{2}$ Queensland Health Scientific Services, Queensland Government, Coopers Plains, Queensland 4108, Australia \\ ${ }^{3}$ School of Biomedical Sciences, University of Queensland, St. Lucia, Queensland 4072, Australia \\ ${ }^{4}$ Turtle and Marine Ecosystems Centre, Department of Fisheries Malaysia, Rantau Abang, Terengganu 23050, Malaysia \\ ${ }^{5}$ Present address: Centre for Marine Environmental Research and Innovative Technology, City University of Hong Kong, \\ Kowloon, Hong Kong SAR China \\ ${ }^{6}$ Present address: School of Medicine, University of Tasmania, Sandy Bay, Tasmania 7005, Australia \\ ${ }^{7}$ Present address: Marine Park Department of Malaysia, Ministry of Natural Resources and Environment, \\ Federal Government Administration Centre, Putrajaya 62574, Malaysia
}

\begin{abstract}
Persistent organic pollutants (POPs), such as polychlorinated biphenyls (PCBs), organochlorine pesticides (OCPs) and polybrominated diphenyl ethers (PBDEs), have a wide range of toxic effects on humans and wildlife, and have been reported in a number of endangered sea turtle populations. The present study screened for POPs in a green sea turtle Chelonia mydas population in Peninsular Malaysia and investigated the maternal transfer and effects of POPs on embryonic development. At the Ma'Daerah Turtle Sanctuary, blood, eggs and hatchling blood were collected from 11 nesting female C. mydas. Samples were analysed for 83 PCBs, 23 OCPs and 19 PBDEs using gas chromatography with tandem mass spectrometry. The chemical profiles of eggs from individual turtles were significantly different, indicating variable contaminant uptake during foraging. There was evidence of maternal transfer of POPs to eggs and hatchlings, with significant correlations in sum of PCBs $(\Sigma \mathrm{PCB})$, sum of PBDEs ( $\mathrm{PBDE}), \gamma$-hexachlorocyclohexane $(\gamma-\mathrm{HCH})$, trans-chlordane and mirex concentrations between maternal blood and eggs $\left(p<0.05, R^{2}<0.71\right)$, between eggs and hatchling blood ( $\left.p<0.05, R^{2}<0.83\right)$, and between maternal and hatchling blood $\left(p<0.05, R^{2}<0.61\right)$. In addition, there was congener-specific transfer of PCBs with less lipophilic congeners (e.g. PCB 99) more readily transferred to hatchlings than the more lipophilic congeners (e.g. PCBs $180+193$ ) There was also a significant correlation between increasing egg POP concentration and decreasing hatchling mass:length ratio. POPs may therefore have subtle effects on the development of C. mydas eggs, which may compromise offshore dispersal and predator avoidance.
\end{abstract}

KEY WORDS: Chelonia mydas $\cdot$ Persistent organic pollutants $\cdot$ Maternal transfer $\cdot$ Contamination profiles

Resale or republication not permitted without written consent of the publisher

\section{INTRODUCTION}

Persistent organic pollutants (POPs), such as polychlorinated biphenyls (PCBs), organochlorine pesticides (OCPs) and polybrominated diphenyl ethers
(PBDEs), have been reported in a number of sea turtle populations. In addition, these chemicals have been correlated with health parameters in free-ranging sea turtles (Keller et al. 2004a, 2006a,b), and embryonic development in other oviparous reptiles (Bergeron et 
al. 1994, Guillette et al. 1996, Guillette \& Crain 1996, Bishop et al. 1998, Willingham \& Crews 1999, de Solla et al. 2008). As sea turtles generally do not feed during the breeding season, the contamination of sea turtles will be influenced by the contamination of their foraging areas (Bjorndal 1985, 1997). Furthermore, due to the lipophilic properties of these compounds and the mobilisation of lipids by sea turtles for egg production (Kwan 1994), it is likely that POPs are transferred from nesting females to eggs and hatchlings during reproduction. This may have consequences for hatchling development, due to the high sensitivity of developing sea turtle embryos to disturbance. However, there is currently limited information on POPs in sea turtle populations or the maternal transfer of these chemicals and the effects this may have on the reproductive success of nesting populations.

Green turtle Chelonia mydas nesting populations are generally comprised of individuals that have migrated from a wide range of foraging grounds (Liew et al. 1995, Cheng 2000, Godley et al. 2002, Seminoff et al. 2008). During their reproductive years, C. mydas show strong fidelity to these foraging and breeding sites, which can be up to thousands of kilometres apart (Carr 1964, Carr \& Carr 1972, Limpus et al. 1992, Lohmann et al. 1999). The contamination of marine vertebrates occurs nearly exclusively though feeding (Newman \& Unger 2003). Therefore, as nesting female C. mydas do not feed during migration or nesting (Bjorndal 1997), their POP concentrations are likely to reflect the contamination in their foraging areas. The contamination of a nesting C. mydas population is therefore expected to be variable and presents considerable conservation challenges, in terms of managing contamination in remote foraging areas.

Maternal transfer of POPs to offspring is well documented in marine mammals (Aguilar \& Borrell 1994, Debier et al. 2003, Miranda-Filho et al. 2007), birds (Fisk \& Johnston 1998) and oviparous reptiles (Kelly et al. 2008). In freshwater snapping turtles Chelydra serpentina, egg concentrations of PCBs, DDTs, mirex, octachlorostyrene and HCB were significantly correlated with concentrations in the blood, liver, muscle and adipose tissue of adult females (Hebert et al. 1993, Pagano et al. 1999, Kelly et al. 2008). Similarly, in leatherback sea turtles Dermochelys coriacea, significant correlations have been found between blood and egg samples containing DDTs, PCBs and PBDEs (Stewart et al. 2007). These results indicate that nesting female turtles can incorporate POPs into eggs during vitellogenesis and ovposition (Guillette \& Crain 1996). However, no studies to date have investigated the further transfer of POPs from eggs to embryos. Furthermore, in mammals there is evidence of selective transfer of POPs to offspring, with the less lipophilic compounds being more readily transferred (MirandaFilho et al. 2009). However, this remains poorly understood in oviparous reptiles, including sea turtles.

During growth, sea turtle embryos mobilise lipid reserves from the egg yolk to meet developmental requirements (Miller 1985). It is therefore likely that the lipophilic POP contaminants in the yolk are transferred to the hatchlings during this process. In Chelydra serpentina, strong correlations have been observed between egg POP concentrations and abnormalities in hatchlings (Bishop et al. 1994, 1998). This association between hatchling abnormalities and egg POP concentrations may be due to the disruptive effects of these chemicals on the endocrine system during development (Miller 1985, Guillette \& Crain 1996). However, a relationship between POP concentrations and hatchling abnormalities has not been previously investigated for Chelonia mydas or any other sea turtle species, and warrants further investigation.

The aim of the present study was to analyse POP contamination in a nesting population of Chelonia mydas, and investigate the maternal transfer of these chemicals to eggs and embryos and the effects this may have on hatchling development.

\section{MATERIALS AND METHODS}

Egg and blood collection. In June and July 2004, eggs and blood were collected from 11 adult female Chelonia mydas nesting at the Ma'Daerah Turtle Sanctuary, Terengganu, Malaysia (Table 1). Three eggs were randomly collected from each clutch at the time of oviposition. Care was taken to minimise egg contact with the sand to avoid external contamination. Each egg was wrapped in hexane-rinsed aluminium foil and kept frozen $\left(-20^{\circ} \mathrm{C}\right)$ until analysis. Following oviposition, the curved carapace length (CCL) and mass of each nesting female were measured according to Bolten (1999).

At the time of oviposition, 2 to $5 \mathrm{ml}$ of blood was collected from the dorsal cervical sinuses in the neck of the nesting female using a $10 \mathrm{ml}$ syringe with a $21 \mathrm{G} \times 1.25$ " $(3.175 \mathrm{~cm}$ ) needle (Owens \& Ruiz 1980). The eggs not taken for chemical analysis were transferred to a shaded hatchery within $2 \mathrm{~h}$ of oviposition and incubated at a depth of $60 \mathrm{~cm}$. Once the hatchlings emerged, a sample of 5 individuals was randomly collected from each nest. Blood samples (300 to $500 \mu \mathrm{l}$ ) were taken from the dorsal cervical sinuses in the neck using an insulin syringe and pooled for each nest. All blood samples were immediately transferred to glass lithium heparin vacutainer tubes and kept frozen $\left(-20^{\circ} \mathrm{C}\right)$ until analysis.

Clutch incubation and hatchling morphometrics. The incubation of clutches in the hatchery was monitored closely around the expected time of emergence. 
Table 1. Chelonia mydas. Nesting and incubation details of 11 nesting females. CCL: curved carapace length, SCL: straight carapace length. Data are mean \pm SE (range)

\begin{tabular}{|c|c|c|c|c|c|c|}
\hline$\overline{\text { Tag }}$ Nestin & $\begin{array}{l}\text { g details - } \\
\text { CCL }(\mathrm{cm})\end{array}$ & Mass (kg) & Eggs & Egg mass (g) & $\begin{array}{l}\text { Incubation details } \\
\text { Hatchling mass ( } \mathrm{g} \text { ) }\end{array}$ & Mass:SCL $\left(\mathrm{g} \mathrm{mm}^{-1}\right)$ \\
\hline MY4133 & 112.5 & 129 & 130 & $34.6 \pm 0.8(33.1-35.7)$ & $19.5 \pm 0.2(18.0-21.0)$ & $0.43 \pm 0.003(0.41-0.46)$ \\
\hline TF3315 & 111 & 127 & 131 & $37.5 \pm 0.8(36.1-38.9)$ & $22.1 \pm 0.2(20.7-23.7)$ & $0.47 \pm 0.003(0.45-0.49)$ \\
\hline No tags & 99 & 101 & 126 & $36.5 \pm 0.8(35.4-38.1)$ & $21.6 \pm 0.2(19.2-22.9)$ & $0.47 \pm 0.004(0.42-0.50)$ \\
\hline IF2565 & 95 & 80 & 39 & $33.5 \pm 0.3(33.0-34.1)$ & $19.8 \pm 0.1(17.8-20.7)$ & $0.44 \pm 0.003(0.40-0.47)$ \\
\hline TF3321/ TF3319 & 112 & 140 & 134 & $37.6 \pm 0.3(37.3-38.2)$ & $23.8 \pm 0.2(21.3-25.2)$ & $0.51 \pm 0.004(0.47-0.53)$ \\
\hline TF3351/ MY1551 & 103 & 105 & 106 & $34.4 \pm 0.8(33.1-35.8)$ & $21.7 \pm 0.2(20.1-23.4)$ & $0.46 \pm 0.003(0.43-0.49)$ \\
\hline MY1552 & 93 & 72 & 67 & $39.7 \pm 0.4(39.0-40.4)$ & $23.9 \pm 0.1(22.9-24.9)$ & $0.51 \pm 0.002(0.50-0.54)$ \\
\hline MY1602 & 99.5 & 94 & 130 & $36.4 \pm 0.9(34.6-37.5)$ & $20.1 \pm 0.2(18.5-21.4)$ & $0.44 \pm 0.003(0.40-0.46)$ \\
\hline MY0297/ MY1502 & 88.9 & 81 & 101 & $34.4 \pm 1.3(31.8-36.4)$ & $23.1 \pm 0.2(18.0-21.1)$ & $0.51 \pm 0.003(0.46-0.52)$ \\
\hline IF2720 & 113 & 135 & 143 & $34.7 \pm 0.8(33.2-36.1)$ & $20.4 \pm 0.2(18.9-21.8)$ & $0.44 \pm 0.003(0.41-0.47)$ \\
\hline MY1555 & 98.4 & 89 & 80 & $35.7 \pm 0.6(35.0-36.8)$ & $21.8 \pm 0.2(18.6-22.9)$ & $0.48 \pm 0.002(0.41-0.51)$ \\
\hline
\end{tabular}

Immediately following emergence, hatchling mass $( \pm 0.01 \mathrm{~g})$ and the straight carapace length (SCL) were measured $( \pm 0.01 \mathrm{~mm})$, and the mass:SCL ratio was calculated for a random sample of 10 hatchlings from each nest. Carapace, plastron and head scutes were also recorded and each hatchling was assigned an abnormality index based on the number of deviations from a normal scute pattern, as described by Pritchard \& Mortimer (1999) and Miller (1985). The percentage of hatchlings with abnormal scute counts and the mean $( \pm \mathrm{SE})$ of each of hatchling morphometric parameter were also calculated for each nest. Seven days after emergence, nests were excavated to determine hatching and emergence success according to Miller (1999).

Chemical analysis. Entire egg contents (excluding shell) and whole blood samples were analysed for 83 PCB congeners, 23 OCPs and 19 PBDE congeners using gas chromatography with tandem mass spectrometry, following methods developed by van de Merwe et al. (2009a). Briefly, samples were extracted in an accelerated solvent extractor (Dionex) with dichloromethane (OmniSolv grade; Merck). Percent lipid of each sample was determined gravimetrically by transferring a known mass of the extract to a tared aluminium tray and weighing the lipid after all solvent had evaporated. Lipids were removed from the remaining extract using gel permeation chromatography, and deactivated florisil columns were used to further purify the extracts.

Samples were analysed on a Varian 3800 gas chromatograph fitted with a $60 \mathrm{~m}$ VF-5MS GC capillary column $(0.25 \mathrm{~mm}$ interior diameter and $0.32 \mu \mathrm{m}$ film thickness) and a Saturn 2200 mass spectrometer. A 1079 programmable temperature vapourising (PTV) injector was used to inject $20 \mu$ l of each sample and ionisation was performed using electron impact. The limit of detection (LOD) was compound- and samplespecific, although for most compounds, it was $<10 \mathrm{pg}$ $\mathrm{g}^{-1}$ for egg samples and $<35 \mathrm{pg} \mathrm{g}^{-1}$ for blood samples. The analysed values for National Institute of Standards and Technology human serum Standard Reference Material (SRM 1589a) were $84.1 \pm 0.1 \%$ of the certified concentrations (Schantz et al. 2007). Values for avian egg control samples (QC04-ERM1; common murre Uria aalge and thick-billed murre U. lomvia) were $79.5 \pm 0.1 \%$ of the reference concentrations (Vander Pol et al. 2007). Recoveries of mass-labelled internal standards ranged from 30 to $96 \%$, and were $<60 \%$ only for the higher-chlorinated PCBs.

Statistical analysis. The mean $( \pm \mathrm{SE})$ of each POP compound was calculated for maternal blood, eggs and hatchling blood. To investigate differences in POP contamination profiles among clutches, analysis of similarity (ANOSIM) was performed on a Bray-Curtis similarity matrix with no data transformation using Primer v5 (PRIMER-E). Each POP compound was entered as a separate variable and each egg was analysed as an individual sample. Significant differences in the ANOSIM $(p<0.05)$ indicated samples that were different in terms of both the presence and concentration of all 125 POP compounds analysed. A nonmetric multi-dimensional scaling (NMDS) plot was also constructed to further illustrate differences in POP contamination profiles between clutches (PRIMER-E).

To investigate transfer of POPs from nesting females to eggs, and from eggs to hatchlings, linear regressions were performed between maternal blood and egg POP concentrations, and between egg and hatchling blood POP concentrations, respectively. In addition, linear regressions were performed between maternal blood and hatchling blood POP concentrations. To standardise for lipid content, POP concentrations were presented in $\mathrm{ng} \mathrm{g}^{-1}$ lipid. Only the compounds detected in maternal blood, eggs and hatchling blood were analysed in this way. The sum of PCB ( $\Sigma$ PCB) and PBDE ( $\Sigma$ PBDE) concentrations were calculated by summing the 83 PCB and 19 PBDE congeners analysed in each sample, respectively. The remaining OCPs were investigated individually. 
To investigate congener-specific maternal transfer of PCBs, the percent of the $\Sigma$ PCB concentration was calculated for each of the major congeners and the means for maternal blood, eggs and hatchling blood were compared using ANOVA. In cases of ANOVA significance $(p<0.05)$, Tukey's post hoc test was used to determine which tissues were different.

To investigate the effect of POP contamination on hatchling development, regressions were performed between hatchling development parameters and the mean egg sum of POP ( $\Sigma$ POP) concentration for each clutch. Linear regressions were performed between mean egg $\Sigma$ POP concentration and hatching success, emergence success and the percentage of abnormal hatchlings, and means of hatchling mass, SCL, mass: SCL ratio or abnormality index. The influence of egg mass on embryonic development was investigated by performing regressions between mean initial egg mass and any hatchling or nest variable that showed significant regression with mean egg $\Sigma$ POP concentration.

\section{RESULTS}

\section{POP concentrations in nesting females, eggs and hatchlings}

The $\Sigma$ POP concentrations ranged from 727 to $2835 \mathrm{pg} \mathrm{g}^{-1}$ wet mass for nesting female blood, 992 to $1569 \mathrm{pg} \mathrm{g}^{-1}$ wet mass for eggs and 1429 to $3321 \mathrm{pg} \mathrm{g}^{-1}$ wet mass for hatchling blood (Table 2). The concentrations of PCBs were generally the highest and congeners 99, 118, 128, 138, 153, 180, 183 and 193 were the most abundant. The most abundant PBDE congeners were 47, 99 and 153, and trans-chlordane, mirex and $\gamma$-hexachlorocyclohexane $(\gamma-\mathrm{HCH})$ were the only OCPs detected in all 3 sample types. On a wet

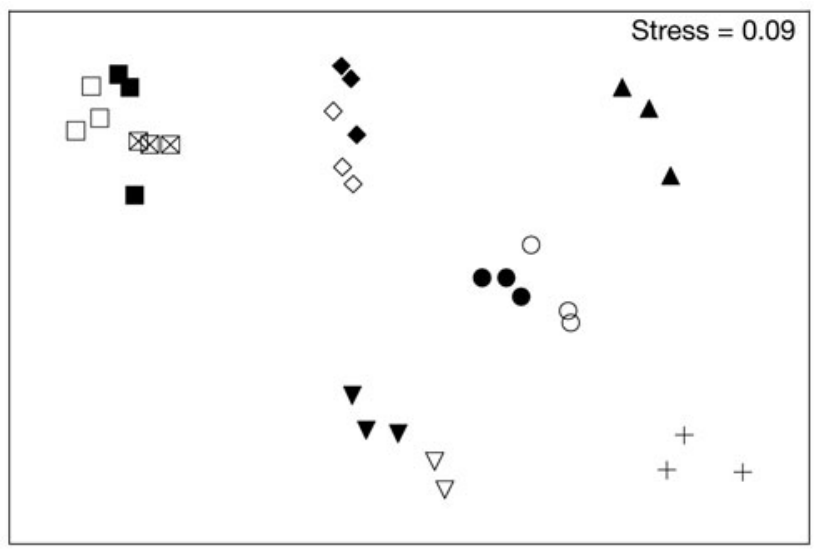

Fig. 1. Chelonia mydas. NMDS plot of egg persistent organic pollutant (POP) profiles for 11 nesting females. Eggs from the same clutch are indicated by the same symbol. Grouping of eggs from the same clutch indicate that within-clutch variation in POP contamination profiles is less than the variation between clutches. There is also some grouping of contamination profiles between clutches, as indicated by clutches with the same symbol shape (either open or filled). Stress $=0.09$, indicating the plot is a good representation of the actual differences between samples

Table 2. Chelonia mydas. The major persistent organic pollutant (POP) compounds in eggs and blood from nesting females and hatchlings. HCH: hexachlorocyclohexane, LOD: limit of detection, PBDE: polybrominated diphenyl ether, PCB: polychlorinated biphenyl

\begin{tabular}{|c|c|c|c|c|c|c|}
\hline \multirow[t]{2}{*}{ POP compound } & \multicolumn{6}{|c|}{ Concentration of POP compound (pg g ${ }^{-1}$ wet mass) } \\
\hline & Mean \pm SE & Range $^{a}$ & Mean \pm SE & Range $^{\mathrm{a}}$ & Mean \pm SE & Range ${ }^{a}$ \\
\hline PCB 99 & $17.4 \pm 1.4$ & $13.0-27.7$ & $39.4 \pm 4.8$ & $22.0-64.3$ & $81.4 \pm 8.2$ & $50.0-124.0$ \\
\hline PCB 118 & $16.4 \pm 1.3$ & $11.6-23.6$ & $33.9 \pm 5.8$ & $18.4-83.6$ & $58.0 \pm 7.1$ & $36.0-105.8$ \\
\hline PCB 128 & $14.1 \pm 1.2$ & $9.9-20.1$ & $28.7 \pm 3.8$ & $16.3-54.4$ & $35.4 \pm 2.5$ & $23.1-47.1$ \\
\hline PCB $138(+158)^{\mathrm{b}}$ & $45.6 \pm 8.9$ & $17.0-94.1$ & $62.9 \pm 13.9$ & $25.8-174.6$ & $101.3 \pm 20.9$ & $46.7-226.7$ \\
\hline PCB $153(+132)^{\mathrm{b}}$ & $65.8 \pm 13.1$ & $25.8-136.4$ & $93.9 \pm 24.4$ & $30.6-288.6$ & $171.9 \pm 43.1$ & $64.7-462.0$ \\
\hline PCB $180+193$ & $53.5 \pm 7.5$ & $33.9-100.4$ & $114.0 \pm 13.5$ & $72.0-202.0$ & $91.1 \pm 11.9$ & $55.0-165.2$ \\
\hline РCB 183 & $14.8 \pm 1.8$ & $9.7-25.9$ & $52.0 \pm 12.1$ & $19.8-134.2$ & $63.8 \pm 12.0$ & $28.0-142.4$ \\
\hline$\Sigma \mathrm{PCB}$ & $553.6 \pm 54.6$ & $392.8-839.4$ & $578.9 \pm 85.6$ & $316.4-1206.5$ & $850.8 \pm 105.2$ & $559.4-1456.6$ \\
\hline trans-chlordane & $18.3 \pm 0.9$ & $13.8-22.3$ & $21.3 \pm 2.7$ & $11.5-33.4$ & $42.5 \pm 4.8$ & $17.1-68.4$ \\
\hline Mirex & $9.4 \pm 1.1$ & $<$ LOD to $12.8(10)$ & $161 \pm 43.0$ & $<$ LOD to $476.3(10)$ & $132.4 \pm 34.0$ & $<$ LOD to $340.6(10)$ \\
\hline$\gamma-\mathrm{HCH}$ & $172.3 \pm 7.4$ & $137.8-207.8$ & $501.1 \pm 59.7$ & $231.3-899.8$ & $939.0 \pm 63.4$ & $634.3-1256.2$ \\
\hline PBDE 47 & $21.5 \pm 1.7$ & $11.1-28.1$ & $13.3 \pm 1.2$ & $7.2-20.1$ & $27.7 \pm 2.7$ & $14.9-41.4$ \\
\hline PBDE 99 & $32.0 \pm 3.6$ & $12.0-54.8$ & $21.3 \pm 3.7$ & $5.0-52.8$ & $55.3 \pm 12.1$ & $8.9-131.8$ \\
\hline PBDE 153 & $27.4 \pm 1.2$ & $20.8-35.2$ & $86.2 \pm 10.3$ & $37.5-151.4$ & $<\mathrm{LOD}$ & - \\
\hline$\Sigma \mathrm{PBDE}$ & $129.3 \pm 8.1$ & $61.7-163.8$ & $120.8 \pm 14.1$ & $57.5-224.3$ & $83.0 \pm 14.4$ & $23.8-173.2$ \\
\hline$\Sigma \mathrm{POP}$ & $1286.8 \pm 66.6$ & $992.3-1568.7$ & $1383.1 \pm 190.0$ & $727.1-2834.9$ & $2047.6 \pm 175.8$ & $1428.9-3320.6$ \\
\hline \% Lipids & $8.9 \pm 0.2$ & $6.8-10.9$ & $1.5 \pm 0.1$ & $1.1-2.1$ & $1.6 \pm 0.1$ & $1.4-2.0$ \\
\hline
\end{tabular}




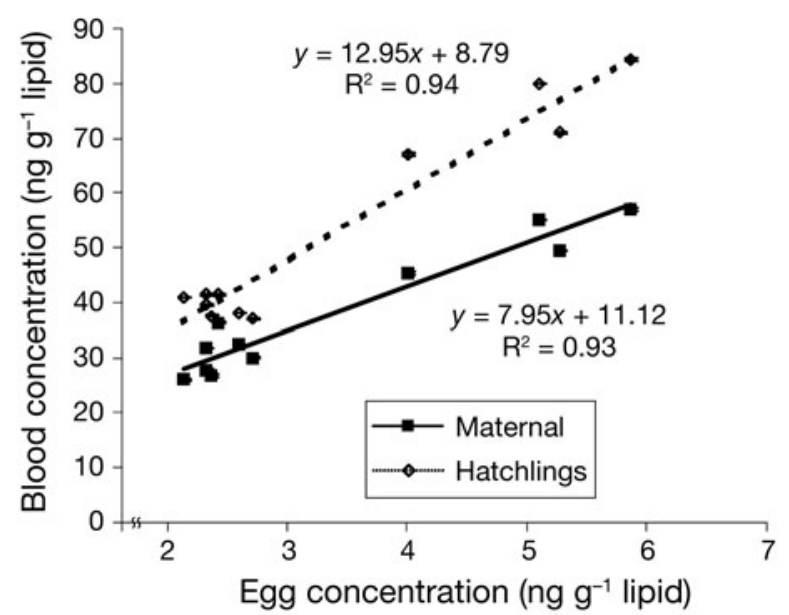

Fig. 2. Chelonia mydas. Relationship between egg and maternal or hatchling blood sum of polychlorinated biphenyls $(\Sigma \mathrm{PCB})$ concentration (mean $\pm \mathrm{SE})$

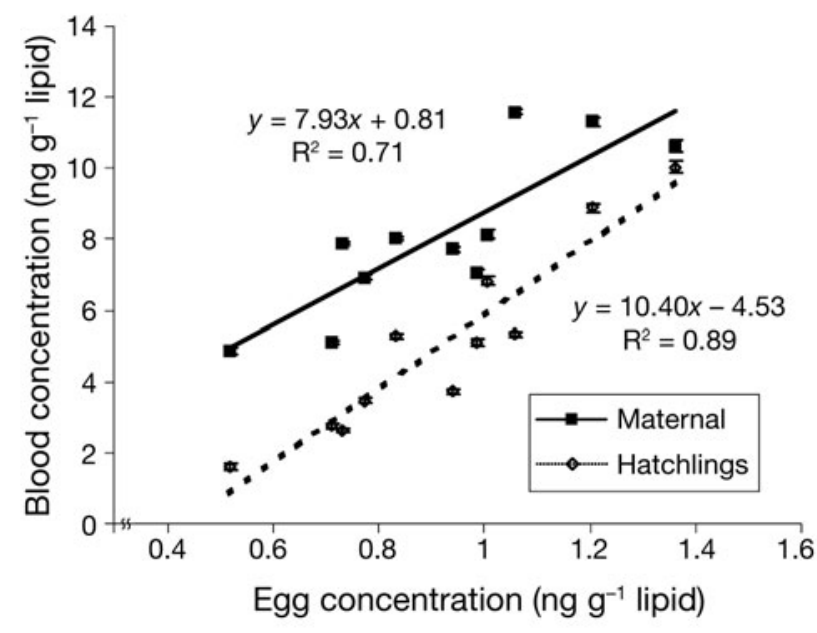

Fig. 3. Chelonia mydas. Relationship between egg and maternal or hatchling blood sum of polybrominated diphenyl ethers ( $\mathrm{PBDE}$ ) concentration (mean $\pm \mathrm{SE}$ )

mass basis, POP concentrations were generally highest in hatchling blood, followed by maternal blood and eggs. However, the number of POP compounds detected in eggs (54) was higher than in the maternal blood (21) and hatchling blood (20).

The egg POP contamination profiles in the present study were significantly different between clutches (ANOSIM: $\mathrm{R}=0.993, \mathrm{p}=0.001$ ), and the NMDS plot illustrated distinct groups of eggs from the 11 nesting female Chelonia mydas (Fig. 1).

\section{Maternal transfer of POPs and correlations with hatchling parameters}

There were significant correlations between maternal blood and eggs, and between eggs and hatchling
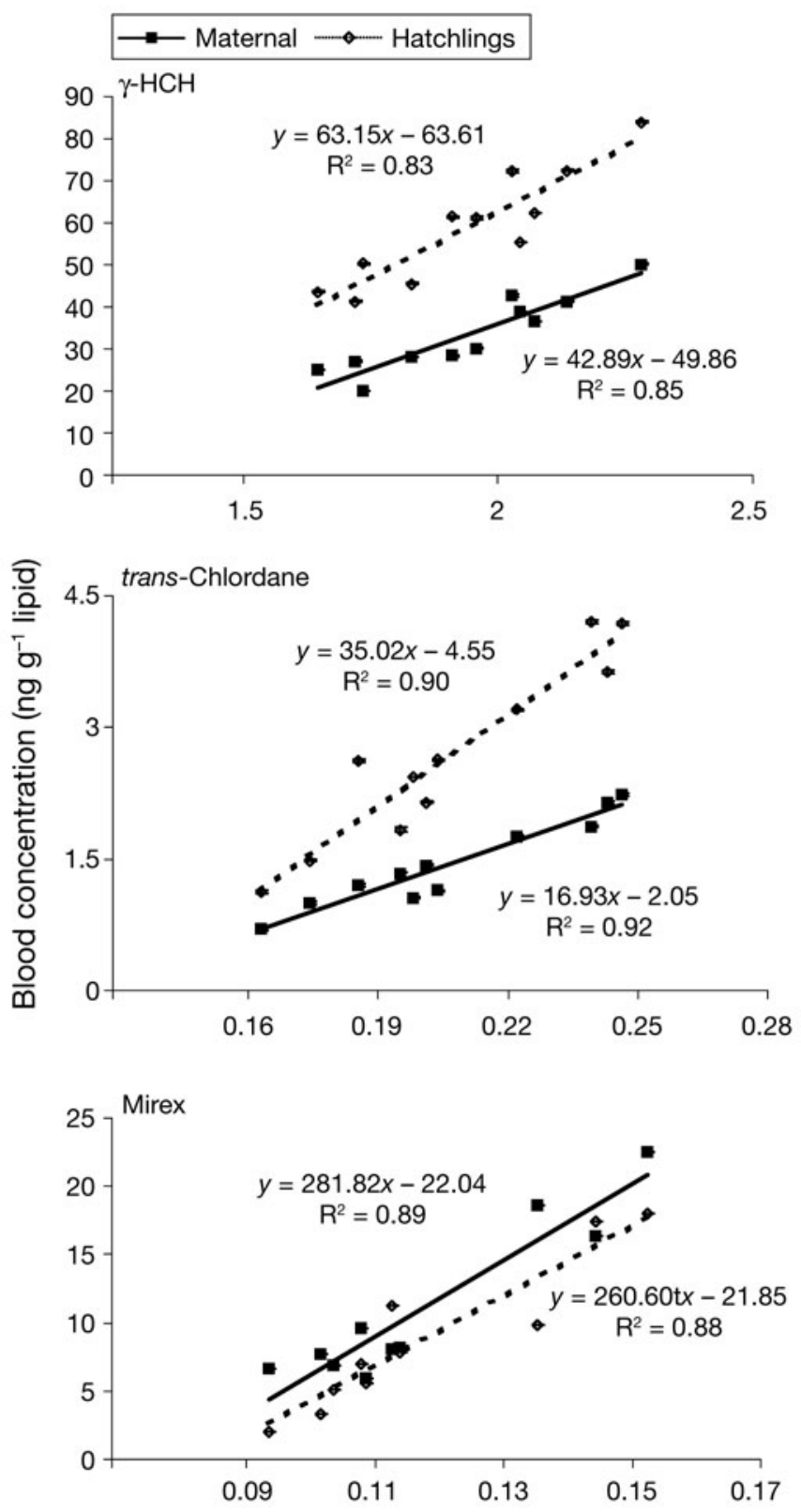

Egg concentration ( $\mathrm{ng} \mathrm{g}^{-1}$ lipid)

Fig. 4. Chelonia mydas. Relationship between egg and maternal or hatchling blood $\gamma$-hexachlorocyclohexane $\left(\gamma-\mathrm{HCH}_{\text {; }}\right.$ upper panel), trans-chlordane (middle panel) and mirex (lower panel) concentrations (mean $\pm \mathrm{SE}$ )

blood for $\Sigma$ PCBs (Fig. 2; $\mathrm{R}^{2}>0.93$, p < 0.005), $\Sigma$ PBDEs (Fig. $3 ; \mathrm{R}^{2}>0.71, \mathrm{p}<0.005$ ) and the OCPs $\gamma-\mathrm{HCH}$, trans-chlordane and mirex (Fig. $4 ; \mathrm{R}^{2}>0.83, \mathrm{p}<0.005$ ). This represented all compounds that were detected in all 3 tissue types. In addition, maternal blood was significantly correlated to hatchling blood for all of the POP compounds and groups $\left(\mathrm{R}^{2}>0.61, \mathrm{p}<0.005\right)$. Significant differences were also observed in the $\mathrm{PCB}$ 
congener composition between maternal blood, eggs and hatchling blood (Fig. 5; p < 0.05). PCB 99 made up a significantly greater percentage of the $\Sigma$ PCB concentration in the hatchling blood $(9.9 \pm 1.3 \%)$, compared to eggs and maternal blood $(6.2 \pm 1.1 \%$ and $7.1 \pm 1.3 \%$, respectively), while PCBs $180+193$ made up a larger percentage of the $\Sigma \mathrm{PCB}$ concentration in the maternal blood and eggs $(20.5 \pm 2.5 \%$ and $17.9 \pm 2.4 \%$, respectively), compared to hatchling blood $(10.8 \pm 1.6 \%)$.

The mass:SCL ratio of hatchlings was significantly correlated with the mean egg $\Sigma$ POP concentration (Fig. $6 ; \mathrm{R}^{2}=0.65, \mathrm{p}=0.02$ ). However, there were no relationships between mean egg $\Sigma$ POP concentrations and hatching success, emergence success, percentage of abnormal hatchlings, hatchling mass, hatchling SCL or hatchling abnormality index ( $p>0.05)$.

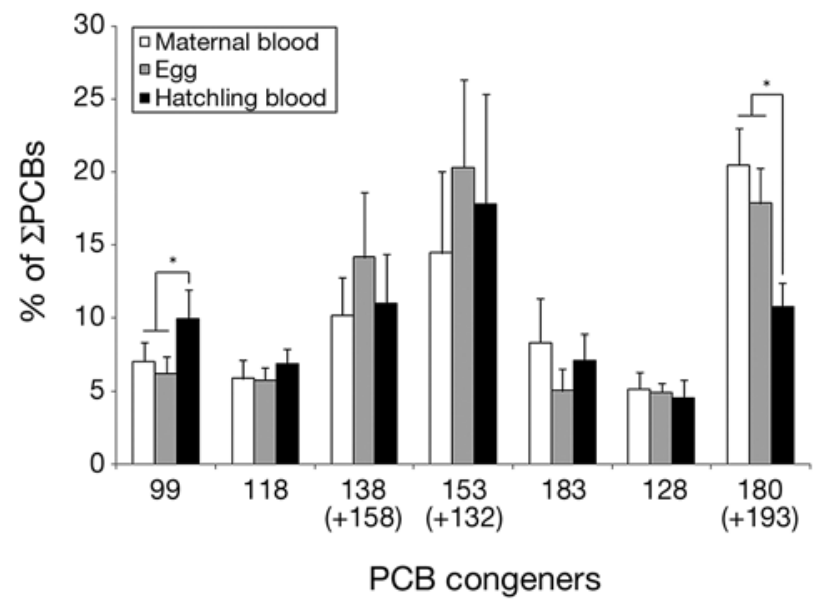

Fig. 5. Chelonia mydas. Congener-specific accumulation (mean $+\mathrm{SD}$ ) of polychlorinated biphenyls (PCBs) in maternal blood, eggs and hatchling blood ( $\mathrm{n}=11$ for each sample type). ${ }^{*} \mathrm{p}<0.05$

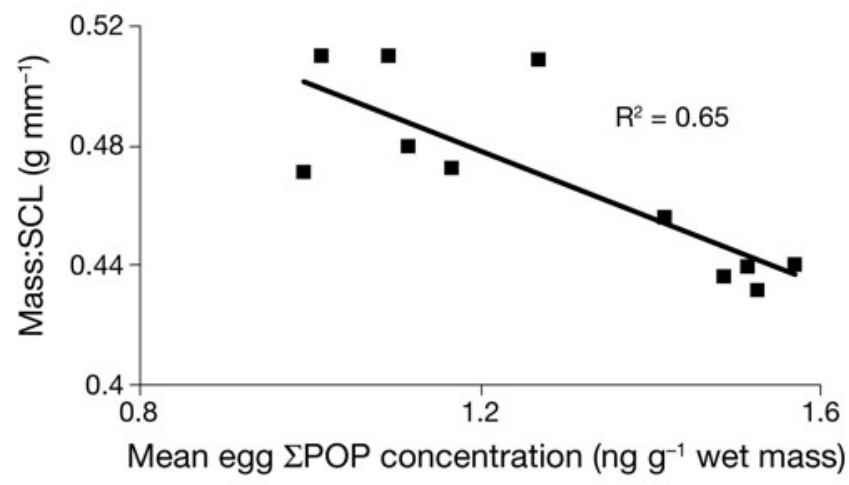

Fig. 6. Chelonia mydas. Relationship between the sum of persistent organic pollutants ( $\Sigma \mathrm{POP}$ ) concentration (mean $\pm \mathrm{SE}$ ) in egg and mean hatchling mass:straight carapace length $(\mathrm{SCL})$ ratio $(\mathrm{SE}<0.005)$

\section{DISCUSSION}

\section{POPs in green turtles of Peninsular Malaysia}

The mean $\Sigma$ POP concentrations in maternal blood $\left(1287 \pm 67 \mathrm{pg} \mathrm{g}^{-1}\right.$ wet mass) and eggs (1383 $\pm 190 \mathrm{pg}$ $\mathrm{g}^{-1}$ wet mass) in the present study were similar to levels observed in concurrent studies on Chelonia mydas eggs from Peninsular Malaysia $\left(1097 \pm 433 \mathrm{pg} \mathrm{g}^{-1}\right.$ wet mass; van de Merwe et al. 2009b) and blood from rehabilitating Chelonia mydas subadults from Australia $\left(929 \pm 170\right.$ pg g $^{-1}$ wet mass; van de Merwe et al. 2009c). In relation to other sea turtle species, lipid-normalised maternal and hatchling blood concentrations of mirex in the present study ( 6 to 23 and 2 to $18 \mathrm{ng} \mathrm{g}^{-1}$ lipid, respectively) were similar to concentrations in the blood of free-ranging juvenile loggerhead turtles Caretta caretta from North Carolina, USA (<LOD to $20.5 \mathrm{ng} \mathrm{g}^{-1}$ lipid; Keller et al. 2004b). However, the concentrations of trans-chlordane (0.7 to 2.2 and 1.1 to $4.2 \mathrm{ng} \mathrm{g}^{-1}$ lipid for maternal and hatchling blood, respectively) and $\mathrm{SPCB}$ (26 to 57 and 37 to $84 \mathrm{ng} \mathrm{g}^{-1}$ lipid for maternal and hatchling blood, respectively) in the present study were up to 100 times lower than concentrations in Caretta caretta juveniles (LOD to 12.8 and 1020 to $2810 \mathrm{ng} \mathrm{g}^{-1}$ lipid, respectively; Keller et al. 2004b). This could be expected due to the higher trophic level occupied by Caretta caretta and the vast geographical separation of the populations sampled. In addition, the $\Sigma$ PCB wet mass concentrations in the eggs of the present study ( 0.39 to $0.84 \mathrm{ng} \mathrm{g}^{-1}$ wet mass) were considerably lower than Chelonia mydas eggs from Ascension Island (20 to $220 \mathrm{ng} \mathrm{g}^{-1}$ wet mass; Thompson et al. 1974). Similarly, lipid-normalised egg $\mathrm{PCB}$ concentrations (2.5 to $5.9 \mathrm{ng} \mathrm{g}^{-1}$ lipid) were significantly lower than Caretta caretta eggs sampled in Florida, USA ( 7 to $3930 \mathrm{ng} \mathrm{g}^{-1}$ lipid; Alava et al. 2006).

The relative concentrations of the different POP compounds in the present study were also comparable with the contamination profiles of mussels and fish analysed within the Southeast Asian region (Kannan et al. 1995, Tanabe et al. 2000). These studies found regional variation in these concentrations, although PCBs and DDTs were generally highest, while chlordanes and HCHs were lower. The absence of DDTs in the present study is a conspicuous discrepancy from these previous studies on mussels and fish. However, the detection of DDE in Chelonia mydas eggs from a concurrent study (J. P. van de Merwe unpubl.) in Peninsular Malaysia and the reliability of the analytical method indicate that the absence of DDE is unlikely to be due to analytical error. Satellite tracking studies on the Ma'Daerah and adjacent C. mydas populations indicate that these turtles often migrate to foraging areas within Southeast Asia far removed from 
industrialised cities and agricultural areas (Liew et al. 1995, van de Merwe et al. 2009d). This may reduce the exposure of the C. mydas in the present study to DDTs, resulting in the absence of these chemicals in eggs and blood of the turtles analysed. In addition, the presence of trans-chlordane in the present study without cischlordane or the nonachlors is unusual for sea turtle samples (e.g. Keller et al. 2004b,c). However, detection of chlordanes at low concentrations is difficult using electron-impact ionisation due to extensive fragmentation. The concentration of trans-chordane in the present study may therefore represent an underestimation of the total chlordanes in this C. mydas population.

The significantly different POP profiles in the Chelonia mydas clutches gives an indication of the variation in POP contamination of this nesting population. As discussed in the 'Introduction', the contamination of adult female green turtles will be strongly influenced by the contamination of the areas in which they forage. A recent study on this Ma'Daerah nesting population found that individual C. mydas migrate to a number of different foraging grounds (in Vietnam, Indonesia and Borneo Malaysia) that may be under threat from varying levels of chemical contamination (van de Merwe et al. 2009d). The different POP profiles observed in the present study may therefore reflect different foraging grounds used by this nesting population. However, the amount of variation in POP profiles that represents animals using different foraging areas remains unclear. There are a number of factors that may complicate this interpretation, such as the age of the animals (an indication of duration of exposure) and the variations in contamination of food sources within foraging areas. Nevertheless, the variation in POP profiles observed in the present study indicates that animals are being exposed to different types and concentrations of POP compounds, and highlights the challenge of managing contamination in C. mydas nesting populations.

\section{Maternal transfer of POPs}

The correlations between maternal blood, eggs and hatchling blood POP concentrations indicates that these chemicals are being transferred from nesting female Chelonia mydas to eggs and hatchlings. Sea turtles mobilise lipids to meet the metabolic demands of migration and egg production (Kwan 1994, Hamann et al. 2002). Therefore, due to the lipophilic properties of POPs, it is likely that these chemicals are transferred from nesting females as lipids are mobilised for yolk production. The transfer of POPs from nesting females to eggs and hatchlings may be a mechanism of chemical off-loading for adult female C. mydas. However, due to the vulnerability of developing embryos to dis- turbance, the transfer of chemicals may also have conservation implications for C. mydas populations.

The results of the present study also indicate that the transfer of POPs from eggs to hatchlings may be compound-specific, related to lipophilicity. PCB 99 made up a larger percentage of the $\Sigma$ PCB concentration in hatchling blood, compared to congeners 180 and 193, indicating that the less lipophilic congeners may be preferentially transferred from eggs to hatchlings. Alternatively, the lower proportion of PCB 180 and 193 in the blood of hatchlings may indicate that the highly lipophilic congeners are more quickly accumulated into the fatty tissue of hatchlings and/or that hatchlings have mechanisms for metabolising these congeners. These results are supported by previous studies on seals that found strong inverse correlations between the $\log K_{\mathrm{ow}}$ (i.e. lipophilicity) and transfer rate from dams to pups (Miranda-Filho et al. 2009). This congener-specific transfer of PCBs may have implications for hatchling development and survival. Generally speaking, less-chlorinated PCBs have higher toxic equivalency factors (TEFs) than more-chlorinated PCBs, although the position of the chlorine atoms also influences congener toxicity (Van den Berg et al. 1998). Preferential transfer of the less lipophilic, more toxic PCB congeners may therefore increase the risks of PCB exposure in Chelonia mydas hatchlings.

The strong correlations between maternal blood and egg POP concentrations also support the use of egg samples to predict POP contamination of adult female Chelonia mydas. Furthermore, due to the low variability in POP concentrations within clutches, a small sample (e.g. 3 eggs, as in the present study) would be sufficient for this analysis. The collection of eggs for contamination screening is a much simpler sampling method than collecting blood from nesting females. Nesting under bushes and shrubs, as well as the short window of opportunity between oviposition and when the front flippers are engaged in nest filling, limits the access for blood sampling of nesting female sea turtles. Furthermore, eggs (30 to $50 \mathrm{~g}$ ) represent a relatively higher sample mass compared to blood samples (10 to $15 \mathrm{~g}$ ), and have significantly higher lipid content. This allows lower LODs to be reached under current methods and therefore increases the likelihood of identifying more compounds in each sample. Although egg sampling is destructive as it prevents the incubation of the eggs sampled, 3 eggs from a clutch represents $<0.5 \%$ of the reproductive output for each adult female C. mydas over a nesting season. Alternatively, the use of undeveloped eggs at the end of incubation could be explored to further reduce the destructive nature of egg sampling. However, further studies would need to be performed to determine if the POP concentrations in the eggs change over the duration of incubation and 
whether there were any external nest influences on egg POP concentrations during this period.

\section{Effects of POPs on hatchling development}

The significant negative correlation between egg $\Sigma$ POP concentration and mass:SCL ratio (a measure of body condition) of hatchlings (see Fig. 6) may indicate an effect of POPs on the embryonic development of Chelonia mydas. A previous study on juvenile loggerhead turtles Caretta caretta reported negative correlations between organochlorine blood concentrations and body condition, as well as indicators of immune function, anaemia, kidney function, metabolism and glucose regulation (Keller et al. 2006b). The mass:SCL ratio may therefore be an early indicator of the effects of POPs on sea turtle development, although direct effects of POPs on sea turtles have not been established. Podreka et al. (1998) exposed Chelonia mydas eggs to 1,1-bis-(4-chlorophenyl)-2,2-dichloroethene $\left(p, p^{\prime}\right.$-DDE), but found no effect on sex reversal, hatch success or hatchling development for predicted egg concentrations of up to $543 \mathrm{ng} \mathrm{g}^{-1}$ wet mass. However, they did not investigate more subtle effects of DDE on hatchling growth and development. Further manipulative experiments may be warranted to investigate nonlethal effects of POPs on the development and survival of sea turtle hatchlings.

The mechanism(s) behind the possible effects of POPs on mass:SCL ratios of Chelonia mydas hatchlings can only be speculative. In a recent study on glaucous gulls Larus hyperboreus, females contaminated with POPs produced eggs with reduced lipid content (although no reduction in overall egg mass), indicating a disruption to resource allocation during egg production (Verboven et al. 2009). This may be due to effects on endocrine processes, such as production of estrogen in the ovaries, which stimulates the liver to produce vitellogenin, a precursor to egg yolk formation (Etches 1996). If similar mechanisms occur in sea turtles, then less lipids in eggs of contaminated nesting females would be available to hatchlings for growth. Alternatively, hatchlings developing in contaminated eggs may be less able to utilise the yolk for growth because they have other metabolic demands associated with dealing with toxic stress. These factors may lead to reduced mass of hatchlings, reflected by the reduced mass:SCL ratios observed in the present study. Although there are a number of environmental factors, such as nest temperature and moisture, that can also influence the growth of oviparous reptile embryos (Booth \& Astill 2001, Packard \& Packard 2001), the hatchery incubation of the eggs in the present study ensured that environmental factors remained similar between clutches. Furthermore, there was no significant correlation between hatchling mass:SCL and initial egg mass (linear regression: $\mathrm{R}^{2}=0.22, \mathrm{p}=0.15$ ), reducing the likelihood of maternal factors being responsible for the differences in mass:SCL ratios observed in the present study.

In sea turtle hatchlings, a reduced mass:SCL ratio may compromise the duration of offshore dispersal. Sea turtle hatchlings emerge from nests in an energetic frenzy and do not feed in the first 3 to $5 \mathrm{~d}$ as they swim continuously to the safer open ocean waters (Dial 1987, Wyneken \& Salmon 1992). The energy demands of offshore dispersal must therefore be met by the store of residual yolk that they have at the time of emergence (Miller 1985). A decrease in mass:SCL ratio of sea turtle hatchlings could indicate reduced residual yolk and hence reduce the duration of offshore dispersal. In addition to compromising offshore dispersal, reduced mass:SCL ratio may also indicate increased susceptibility to predation. There is evidence that larger turtle hatchlings survive better than their smaller conspecifics due to superior locomotion and increased mobility and agility, which reduce bird and fish predation (Haskell et al. 1996, Janzen et al. 2000a,b).

Acknowledgements. Staff at the Department of Fisheries, Malaysia provided logistical support for obtaining samples from Peninsular Malaysia. Special thanks to J. M. Keller from the National Institute of Standards and Technology (NIST), South Carolina, USA, for supply of calibrants and internal standards for POP measurements. Thanks also to all QHSS staff for assistance in the laboratories, and R. Bak and B. Monczko from Griffith University, who assisted with setup and maintenance of the GC-MS/MS instrumentation. This work was supported by the Australian Research Council (Linkage Grant -LP0455513) and carried out under a Griffith University animal ethics permit (EAS/04/04aec).

\section{LITERATURE CITED}

Aguilar A, Borrell A (1994) Reproductive transfer and variation of body load of organochlorine pollutants with age in fin whales (Balaenoptera physalus). Arch Environ Contam Toxicol 27:546-554

Alava JJ, Keller JM, Kucklick JR, Wyneken J, Crowder L, Scott GI (2006) Loggerhead sea turtle (Caretta caretta) egg yolk concentrations of persistent organic pollutants and lipid increase during the last stage of embryonic development. Sci Total Environ 367:170-181

Bergeron JM, Crews D, McLachlan JA (1994) PCBs as environmental estrogens: turtle sex determination as a biomarker of environmental contamination. Environ Health Perspect 102:780-781

Bishop CA, Brown GP, Brooks RJ, Lean DRS, Carey JH (1994) Organochlorine contaminant concentrations in eggs and their relationship to body size and clutch characteristics of the female common snapping turtle (Chelydra serpentina serpentina) in Lake Ontario, Canada. Arch Environ Contam Toxicol 27:82-87

Bishop CA, Ng P, Pettit KE, Kennedy SW, Stegeman JJ, Norstrom RJ, Brooks RJ (1998) Environmental contamina- 
tion and developmental abnormalities in eggs and hatchlings of the common snapping turtle (Chelydra serpentina serpentina) from the Great Lakes-St Lawrence River basin (1989-91). Environ Pollut 101:143-156

Bjorndal KA (1985) Nutritional ecology of sea turtles. Copeia 1985:736-751

Bjorndal KA (1997) Foraging ecology and nutrition of sea turtles. In: Lutz PL, Musick JA (eds) The biology of sea turtles. CRC Press, Boca Raton, FL, p 199-231

Bolten AB (1999) Techniques for measuring sea turtles. In: Eckert KL, Bjorndal KA, Abreu-Grobois FA, Donnelly M (eds) Research and management techniques for the conservation of sea turtles, Vol 4. IUCN/SSC Marine Turtle Specialist Group, Washington, DC, p 119-123

Booth DT, Astill K (2001) Incubation temperature, energy expenditure and hatchling size in the green turtle (Chelonia mydas), a species with temperature-sensitive sex determination. Aust J Zool 49:389-396

Carr A (1964) Transoceanic migrations of the green turtle. Bioscience 14:49-52

> Carr A, Carr MH (1972) Site fixity in the Caribbean green turtle. Ecology 53:425-429

> Cheng IJ (2000) Post-nesting migrations of green turtles (Chelonia mydas) at Wan-An Island, Penghu Archipelago, Taiwan. Mar Biol 137:747-754

de Solla SR, Fernie KJ, Ashpole S (2008) Snapping turtles (Chelydra serpentina) as bioindicators in Canadian Areas of Concern in the Great Lakes Basin. II. Changes in hatching success and hatchling deformities in relation to persistent organic pollutants. Environ Pollut 153:529-536

> Debier C, Pomeroy PP, Dupont C, Joiris C and others (2003) Quantitative dynamics of PCB transfer from mother to pup during lactation in UK grey seals Halichoerus grypus. Mar Ecol Prog Ser 247:237-248

Dial BE (1987) Energetics and performance during nest emergence and the hatchling frenzy in loggerhead sea turtles (Caretta caretta). Herpetologica 43:307-315

Etches RJ (1996) Reproduction in poultry. CAB International, Wallingford

Fisk AT, Johnston TA (1998) Maternal transfer of organochlorines to eggs of Walleye (Stizostedion vitreum) in Lake Manitoba and Western Lake Superior. J Gt Lakes Res 24: 917-928

Godley BJ, Richardson S, Broderick AC, Coyne MS, Glen F, Hays GC (2002) Long-term satellite telemetry of the movements and habitat utilisation by green turtles in the Mediterranean. Ecography 25:352-362

Guillette LJJ, Crain DA (1996) Endocrine-disrupting contaminants and reproductive abnormalities in reptiles. Comments Toxicol 5:381-399

Guillette LJJ, Arnold SF, McLachlan JA (1996) Ecoestrogens and embryos - is there a scientific basis for concern? Anim Reprod Sci 42:13-24

Hamann M, Limpus CJ, Whittier JM (2002) Patterns of lipid storage and mobilisation in female green sea turtles (Chelonia mydas). J Comp Physiol A 172:485-493

> Haskell A, Graham TE, Griffin CR, Hestbeck JB (1996) Size related survival of headstarted redbelly turtles (Pseudemys rubriventris) in Massachusetts. J Herpetol 30:524-527

Hebert CE, Glooschenko V, Haffner GD, Lazar R (1993) Organic contaminants in snapping turtle (Chelydra serpentina) populations from southern Ontario, Canada. Arch Environ Contam Toxicol 24:35-43

> Janzen FJ, Tucker JK, Paukstis GL (2000a) Experimental analysis of an early life-history stage: avian predation selects for larger body size of hatchling turtles. J Evol Biol 13:947-954
Janzen FJ, Tucker JK, Paukstis GL (2000b) Experimental analysis of an early life-history stage: selection on size of hatchling turtles. Ecology 81:2290-2304

> Kannan K, Tanabe S, Tatsukawa R (1995) Geographical distribution and accumulation features of organochlorine residues in fish in tropical Asia and Oceania. Environ Sci Technol 29:2673-2683

Keller JM, Kucklick JR, Stamper MA, Harms CA, McClellanGreen PD (2004a) Associations between organochlorine contaminant concentrations and clinical health parameters in loggerhead sea turtles from North Carolina, USA. Environ Health Perspect 112:1074-1079

Keller JM, Kucklick JR, Harms CA, McClellan-Green PD (2004b) Organochlorine contaminants in sea turtles: correlations between whole blood and fat. Environ Toxicol Chem 23:726-738

Keller JM, Kucklick JR, McClellan-Green PD (2004c) Organochlorine contaminants in loggerhead sea turtle blood: extraction techniques and distribution among plasma and red blood cells. Arch Environ Contam Toxicol 46:254-264

> Keller JM, McClellan-Green PD, Kucklick JR, Keil DE, Peden-Adams MM (2006a) Effects of organochlorine contaminants on loggerhead sea turtle immunity: comparison of a correlative field study and in vitro exposure experiments. Environ Health Perspect 114:70-76

Keller JM, Peden-Adams MM, Aguirre AA (2006b) Immunotoxicology and implications for reptilian health. In: Gardner SC, Oberborster E (eds) Toxicology of reptiles. CRC Press, Boca Raton, FL, p 199-240

Kelly SM, Eisenreich KM, Barker JE, Rowe CL (2008) Accumulation and maternal transfer of polychlorinated biphenyls in snapping turtles of the upper Hudson River, New York, USA. Environ Toxicol Chem 27:2565-2574

Kwan D (1994) Fat reserves and reproduction in the green turtle, Chelonia mydas. Wildl Res 21:257-266

Liew HC, Chan EH, Papi F, Luschi P (1995) Long distance migration of green turtles from Redang Island: the need for regional cooperation in sea turtle conservation. In: Devaux B (ed) Proc Int Congress Chelonian Conservation, July 6-10. SOPTOM, Gonfaron, p 73-75

Limpus CJ, Miller JD, Parmenter CJ, Reimer D, McLachlan N, Webb R (1992) Migration of green (Chelonia mydas) and loggerhead (Caretta caretta) turtles to and from eastern Australian rookeries. Wildl Res 19:347-358

Lohmann KJ, Hester JT, Lohmann CMF (1999) Long-distance navigation in sea turtles. Ethol Ecol Evol 11:1-23

Miller JD (1985) Embryology of marine turtles. In: Gans C (ed) Biology of the reptilia, Vol 14. Development A. John Wiley \& Sons, New York, p 269-328

Miller JD (1999) Determining clutch size and hatching success. In: Eckert KL, Bjorndal KA, Abreu-Grobois FA, Donnelly $M$ (eds) Research and management techniques for the conservation of sea turtles, Vol 4. IUCN/SSC Marine Turtle Specialist Group, Washington, DC, p 119-123

> Miranda-Filho $\mathrm{KC}$, Metcalfe TL, Metcalfe CD, Robaldo RB and others (2007) Residues of persistent organochlorine contaminants in southern elephant seals (Mirounga leonina) from Elephant Island, Antarctica. Environ Sci Technol 41:3829-3835

> Miranda-Filho KC, Metcalfe CD, Metcalfe TL, Muelbert MM and others (2009) Lactational transfer of PCBs and chlorinated pesticides in pups of southern elephant seals (Mirounga leonina) from Antarctica. Chemosphere 75: 610-616

Newman MC, Unger MA (2003) Fundamentals of ecotoxicology. Lewis Publishers, Boca Raton, FL 
Owens DW, Ruiz GJ (1980) New methods of obtaining blood and cerebrospinal fluid from marine turtles. Herpetologica 36:17-20

Packard GC, Packard MJ (2001) Environmentally induced variation in size, energy reserves and hydration of hatchling painted turtles, Chrysemys picta. Funct Ecol 15: 481-489

Pagano JJ, Rosenbaum PA, Roberts RN, Summer GM, Williamson LV (1999) Assessment of maternal contamination burden by analysis of snapping turtle eggs. J Gt Lakes Res 25:950-961

Podreka S, Georges A, Maher B, Limpus CJ (1998) The environmental contaminant DDE fails to influence the outcome of sexual differentiation in the marine turtle Chelonia mydas. Environ Health Perspect 106:185-188

Pritchard PCH, Mortimer JA (1999) Taxonomy, external morphology, and species identification. In: Eckert KL, Bjorndal KA, Abreu-Grobois FA, Donnelly M (eds) Research and management techniques for the conservation of sea turtles. IUCN/SSC Marine Turtle Specialist Group, Washington, DC, p 21-40

Schantz M, Keller J, Leigh S, Patterson D and others (2007) Certification of SRM 1589a PCBs, pesticides, PBDEs, and dioxins/furans in human serum. Anal Bioanal Chem 389: 1201-1208

Seminoff JA, Zárate P, Coyne MS, Foley DG, Parker D, Lyon BN, Dutton PH (2008) Post-nesting migrations of Galápagos green turtles Chelonia mydas in relation to oceanographic conditions: integrating satellite telemetry with remotely sensed ocean data. Endang Species Res 4:57-72

Stewart K, Keller JM, Johnson C, Kucklick JR (2007) Baseline contaminant concentrations in leatherback turtles and maternal transfer to eggs confirmed. In: Rees AF, Frick M, Panagopoulou A, Williams K (eds) Proc 27th Annu Symp Sea Turtle Biology and Conservation. Myrtle Beach, SC, Feb 22-28. NOAA Technical Memorandum NMFSSEFSC-569. p 30

Tanabe S, Prudente MS, Kan-Atireklap S, Subramanian A (2000) Mussel watch: marine pollution monitoring of butyltins and organochlorines in coastal waters of Thailand, Philippines and India. Ocean Coast Manage 43: 819-839

Editorial responsibility: Otto Kinne, Oldendorf/Luhe, Germany
Thompson NP, Rankin PW, Johnston DW (1974) Polychlorinated biphenyls and $p, p^{\prime}$-DDE in green turtle eggs from Ascension Island, South Atlantic Ocean. Bull Environ Contam Toxicol 11:399-403

van de Merwe JP, Whittier JM, Ibrahim K, Hodge M, Lee SY (2009a) Analysing persistent organic pollutants in eggs, blood and tissue of the green sea turtle (Chelonia mydas) using gas chromatography with tandem mass spectrometry (GC-MS/MS). Anal Bioanal Chem 393:1719-1731

van de Merwe JP, Hodge M, Olszowy H, Whittier JM, Ibrahim K, Lee SY (2009b) Chemical contamination of green turtle (Chelonia mydas) eggs in Peninsular Malaysia: implications for conservation and public health. Environ Health Perspect 117:1397-1401

> van de Merwe JP, Hodge M, Olszowy H, Whittier JM, Lee SY (2009c) Using blood samples to estimate persistent organic pollutants and metals in green sea turtles (Chelonia mydas). Mar Pollut Bull (in press) doi:10.1016/j.marpolbul. 2009.11.006

> van de Merwe JP, Ibrahim K, Lee SY, Whittier JM (2009d) Habitat use by green turtles (Chelonia mydas) nesting in Peninsular Malaysia: local and regional conservation implications. Wildl Res 36:637-645

Van den Berg M, Birnbaum L, Bosveld ATC, Brunstrom B and others (1998) Toxic equivalency factors (TEFs) for PCBs, PCDDs, PCDFs for humans and wildlife. Environ Health Perspect 106:775-792

- Vander Pol SS, Ellisor MB, Pugh RS, Becker PR and others (2007) Development of a murre (Uria spp.) egg control material. Anal Bioanal Chem 387:2357-2363

Verboven N, Verreault J, Letcher RJ, Gabrielsen GW, Evans NP (2009) Differential investment in eggs by Arctic-breeding glaucous gulls (Larus hyperboreus) exposed to persistent organic pollutants. Auk 126:123-133

Willingham E, Crews D (1999) Sex reversal effects of environmentally relevant xenobiotic concentrations on the redeared slider turtle, a species with temperature-dependent sex determination. Gen Comp Endocrinol 113:429-435

> Wyneken J, Salmon M (1992) Frenzy and post-frenzy swimming activity in loggerhead, green and leatherback hatchling sea turtles. Copeia 1992:478-484

Submitted: August 5, 2009; Accepted: December 18, 2009 Proofs received from author(s): March 9, 2010 